CLINICAL STUDY

\title{
Cut-off limits of the GH response to GHRH plus arginine test and IGF-I levels for the diagnosis of GH deficiency in late adolescents and young adults
}

Ginevra Corneli ${ }^{1,2}$ Carolina Di Somma ${ }^{3}$. Flavia Prodam ${ }^{1,2}$, Jaele Bellone ${ }^{4}$, Simonetta Bellone ${ }^{2}$ Valentina Gasco ${ }^{4}$, Roberto Baldelli $^{5}$, Silvia Rovere ${ }^{4}$, Harald Jörn Schneider ${ }^{4}$, Luigi Gargantini ${ }^{6}$, Roberto Gastaldi ${ }^{7}$, Lucia Ghizzoni ${ }^{8}$, Domenico Valle $^{9}$, Mariacarolina Salerno ${ }^{10}$, Annamaria Colao ${ }^{3}$, Gianni Bona ${ }^{2}$, Ezio Ghigo ${ }^{4}$, Mohamad Maghnie $^{7}$ and Gianluca Aimaretti ${ }^{1}$

${ }^{1}$ Endocrinology, Department of Clinical and Experimental Medicine, 'Amedeo Avogadro' University of Novara, Via Solaroli, 17, 28100 Novara, Italy, ${ }^{2}$ Division of Pediatrics, Amedeo Avogadro' University of Novara, 28100 Novara, Italy, ${ }^{3}$ Department of Endocrinology, 'Federico II' University of Naples, 80100 Naples, Italy, ${ }^{4}$ Division of Endocrinology and Metabolic Diseases, University of Turin, 10100 Turin, Italy, ${ }^{5}$ Endocrinology Service, Regina Elena Cancer Institute, 00100 Rome, Italy, ${ }^{6}$ Division of Pediatric Endocrinology, Hospital of Treviglio, 24047 Treviglio, Italy, ${ }^{7}$ Department of Pediatrics, IRCCS G. Gaslini, University of Genoa, 16100 Genoa, Italy, ${ }^{8}$ Division of Pediatrics, University of Parma, 8100 Parma, Italy, ${ }^{9}$ Eli-Lilly, Florence, Italy and

${ }^{10}$ Division of Pediatrics, 'Federico II' University of Naples, Naples, Italy

(Correspondence should be addressed to G Aimaretti; Email: gianluca.aimaretti@med.unipmn.it)

\begin{abstract}
Objective: To define the appropriate diagnostic cut-off limits for the GH response to GHRH+arginine (ARG) test and IGF-I levels, using receiver operating characteristics (ROC) curve analysis, in late adolescents and young adults.

Design and methods: We studied 152 patients with childhood-onset organic hypothalamic-pituitary disease (85 males, age (mean \pm s.e.m.): $19.2 \pm 0.2$ years) and 201 normal adolescents as controls (96 males, age: $20.7 \pm 0.2$ years). Patients were divided into three subgroups on the basis of the number of the other pituitary hormone deficits, excluding GH deficiency (GHD): subgroup A consisted of 35 panhypopituitary patients (17 males, age: $21.2 \pm 0.4$ years), subgroup B consisted of 18 patients with only one or with no more than two pituitary hormone deficits (7 males, age: $20.2 \pm 0.9$ years); and subgroup $C$ consisted of 99 patients without any known hormonal pituitary deficits $(60$ males, age: $18.2 \pm 0.2$ years). Both patients and controls were lean (body mass index, BMI $<25 \mathrm{~kg} / \mathrm{m}^{2}$ ). Patients in subgroup A were assumed to be GHD, whereas in patients belonging to subgroups B and C the presence of GHD had to be verified.

Results: For the GHRH + ARG test, the best pair of highest sensitivity (Se; 100\%) and specificity (Sp; 97\%) was found choosing a peak GH of $19.0 \mu \mathrm{g} / \mathrm{l}$. For IGF-I levels, the best pair of highest Se $(96.6 \%)$ and $\mathrm{Sp}(74.6 \%)$ was found using a cut-off point of $160 \mu \mathrm{g} / \mathrm{l}$ (SDS: -1.3$)$. Assuming $19.0 \mu \mathrm{g} / \mathrm{l}$ to be the cut-off point established for GHRH + ARG test, $72.2 \%$ of patients in subgroup B and 39.4\% in subgroup $\mathrm{C}$ were defined as GHD. In patients belonging to group B and $\mathrm{C}$ and with a peak $\mathrm{GH}$ response $<19 \mu \mathrm{g} / \mathrm{l}$ to the test, IGF-I levels were lower than $160 \mu \mathrm{g} / \mathrm{l}$ (or less than $1.3 \mathrm{SDS}$ ) in 68.7 and $41.6 \%$ of patients respectively predicting severe GHD in $85.7 \%$ of panhypopituitary patients (subgroup A). Conclusions: In late adolescent and early adulthood patients, a GH cut-off limit using the GHRH + ARG test lower than $19.0 \mu \mathrm{g} / \mathrm{l}$ is able to discriminate patients with a suspicion of GHD and does not vary from infancy to early adulthood.
\end{abstract}

European Journal of Endocrinology 157 701-708

\section{Introduction}

The clinical features of adult growth hormone deficiency (GHD) are recognizable but not distinctive, so clinical suspicion must be confirmed by biochemical tests. Within an appropriate clinical context, GHD in adults has to be shown by a single provocative testing, provided that it is reproducible with clear normative limits. The insulin tolerance test (ITT) has been indicated as the test of choice while the GH-releasing hormone plus arginine (GHRH $+\mathrm{ARG}$ ) test is considered the best alternative (1-3).

The diagnosis of GHD in late adolescents and young adults, defined as the 'transition period' from 15 to 25 years, represents a major clinical challenge and raises questions about the most appropriate method and cut-off value for diagnosing GHD after completion of growth and puberty (4).

Though the evaluation of spontaneous GH secretion, IGF-I and IGF-binding protein-3 levels could be useful in 
diagnosing GHD in childhood (5) this is not the case in adulthood due to remarkable overlap between GHD and normal subjects (1-3). Thus, the most appropriate reevaluation of somatotroph function in adolescence or young adulthood is likely to be represented by measurement of a serum IGF-I concentration and/or a GH stimulation test (4). In fact, low IGF-I levels can be definitive evidence of persistent severe GHD in subjects with genetic GHD or panhypopituitarism $(4,6,7)$, although normal IGF-I levels never rule out severe GHD (1, 7-10).

The Consensus Statement about the management of the $\mathrm{GH}$-treated adolescent in the transition to adult care stated that $3 \mu \mathrm{g} / \mathrm{l}$ as the cut-off limit in response to ITT used to define severe GHD in adulthood, is too conservative in the transition period (4). Thus, a cut-off limit of the $\mathrm{GH}$ response $<5 \mu \mathrm{g} / \mathrm{l}$ to whatsoever provocative test, which is in between the adult and childhood cut-off limits ( $<3$ and $<7 \mu \mathrm{g} / \mathrm{l}$ respectively), was proposed as a criterion for severe GHD in the transition period (4). However, this assumption was not clearly evidence based. In fact, in pediatric age, the most pronounced $\mathrm{GH}$ response to a stimulation test occurs in late puberty with $\mathrm{GH}$ levels inevitably exceeding $5 \mu \mathrm{g} / \mathrm{l}$ (11). Recently, we defined a peak GH response < $6.1 \mu \mathrm{g} / \mathrm{l}$ as the cut-off limit for ITT in late adolescents and young adults using the receiver operating characteristics (ROC) curve analysis with a 96\% sensitivity (Se) and a $100 \%$ specificity (Sp) (11). This cut-off limit for ITT is higher than that recommended by the Consensus Statement and would therefore avoid false-negative diagnostic responses (11).

GHRH + ARG test demonstrated excellent Se and Sp both in childhood and in adulthood assuming appropriate cut-off limits (12-15). However, for the adolescence and young adults phase (defined as the age period from 15 to 25 years), the reliability of the GHRH + ARG test in confirming childhood onset GHD has not been assessed yet (16-18).

Based on these foregoing matters, the aim of this study was to define the appropriate diagnostic cut-off limits of GH response to the GHRH + ARG test as well as of IGF-I levels and their Se and Sp for the diagnostic accuracy of GHD in late adolescents and young adults, using an appropriate methodology for the ROC curve analysis.

\section{Subjects}

We evaluated the total IGF-I levels and GH response to the GHRH-ARG test in 152 lean patients (85 males and 67 females, age (mean \pm s.e.м.): $19.2 \pm 0.2$ years (range: $15-25$ years), BMI (mean \pm s.e.m.): $20.9 \pm 0.2 \mathrm{~kg} / \mathrm{m}^{2}$ ), all with structural hypothalamicpituitary abnormalities and childhood-onset organic hypothalamic-pituitary disease (Table 1). All the patients considered in this study were diagnosed as GH deficient during childhood. The diagnosis of GHD in childhood had been based on clinical and auxological criteria and evidence of a GH response $<10 \mu \mathrm{g} / \mathrm{l}$ to at least two 'classical' provocative tests (19).

The most common disorders were congenital pituitary diseases in 126 patients $(82.8 \%$; i.e., pituitary hypoplasia, septo-optic dysplasia, ectopic posterior pituitary) and acquired pituitary disease in 26 (17.2\%) (i.e., hypothalamic-pituitary adenomas, craniopharingyomas, and other peripituitary tumors requiring neurosurgery and/or radiotherapy and post-traumatic hypopituitarism; Table 2). The patients were subdivided into three subgroups on the basis of the number of the other pituitary hormone deficits, excluding GHD. The first subgroup consisted of 35 panhypopituitary patients (subgroup A: 17 males and 18 females, age (mean \pm s.e.m.): $21.2 \pm 0.4$ years). They all had secondary hypothyroidism, hypoadrenalism, and hypogonadism; 12 out of 35 patients had also diabetes insipidus. The second subgroup consisted of 18 patients with only one or with no more than two pituitary hormone deficits (subgroup B: 7 males and 11 females, age (mean \pm s.e.m.): $20.2 \pm 0.9$ years). Three patients $(2.5 \%)$ had secondary hypothyroidism, two (1.7\%) secondary hypoadrenalism, six (5.1\%) secondary hypogonadism, two $(3.5 \%)$ had both secondary hypothyroidism and hypoadrenalism, three $(2.5 \%)$ had both secondary hypothyroidism and hypogonadism, and two (1.7\%) had both secondary hypoadrenalism and hypogonadism. The third subgroup consisted of 99 patients without any current known hormonal pituitary deficits (subgroup C: 60 males and 39 females, age (mean \pm s.e.m.): $18.2 \pm 0.2$ years). All patients were studied while on optimized replacement therapy for other pituitary deficits including cortisone acetate, thyroid hormone, transdermal

Table 1 Characteristics of the population studied. Results are expressed as mean \pm S.E.M.

\begin{tabular}{|c|c|c|c|c|}
\hline & \multirow[b]{2}{*}{ Control subjects } & \multicolumn{3}{|c|}{ Patients } \\
\hline & & $\begin{array}{c}\text { Subgroup A } \\
\text { (panhypopituitary } \\
\text { patients) }\end{array}$ & $\begin{array}{l}\text { Subgroup B } \\
\text { (1 or } 2 \text { pituitary } \\
\text { hormone deficits) }\end{array}$ & $\begin{array}{c}\text { Subgroup } \mathrm{C} \\
\text { (no pituitary hormone } \\
\text { deficits known) }\end{array}$ \\
\hline Number & 201 & 35 & 18 & 99 \\
\hline Age (years) & $20.7 \pm 0.2$ & $21.2 \pm 0.4$ & $20.2 \pm 0.9$ & $18.2 \pm 0.2$ \\
\hline Sex (male/female) & $96 / 105$ & $17 / 18$ & $7 / 11$ & $60 / 39$ \\
\hline
\end{tabular}


Table 2 Etiology of hypopituitarism in patients studied.

\begin{tabular}{lccc}
\hline Diagnosis & $\begin{array}{c}\text { Group A } \\
\text { (35 pt.) } n\end{array}$ & $\begin{array}{c}\text { Group B } \\
(18 \text { pt.) } n\end{array}$ & $\begin{array}{c}\text { Group C } \\
(99 \text { pt.) } n\end{array}$ \\
\hline Acquired diseases & & & \\
$\quad$ Pituitary adenomas & 5 & 1 & 1 \\
$\quad$ Craniopharyngiomas & 5 & 4 & 0 \\
$\quad$ Traumatic brain injuries (TBI) & 2 & 4 & 0 \\
$\quad$ Peripituitary lesions & 2 & 1 & 1 \\
Congenital diseases & & & \\
$\quad$ Pituitary hypoplasia & 4 & 2 & 76 \\
$\quad$ Septo-optic dysplasia (SOD) & 3 & 2 & 5 \\
Empty sellae & 14 & 4 & 16 \\
\hline
\end{tabular}

gonadal steroids, i.m. testosterone, and desmopressin, where appropriate.

In all patients studied recombinant human $\mathrm{GH}$ (rhGH) treatment had been discontinued when patients reached their final height, as indicated by growth velocity below $2 \mathrm{~cm} /$ year in the last year of treatment. The reevaluation of the somatotroph function was evaluated by GHRH+ ARG test and total IGF-I levels after at least 3 months of GH therapy (range: 3-24 months).

As a control group, we studied 201 healthy lean late adolescents and young adults (96 males and 105 females; age (mean \pm s.e.m.): $20.7 \pm 0.2$ years (range: 15-25 years), BMI (mean \pm s.e.M.): $21.3 \pm 0.2 \mathrm{~kg} / \mathrm{m}^{2}$ ).

Patients and controls were enrolled in a multi-center study (six pediatric endocrinology centers and two adult endocrinology centers).

All subjects were measured for height and weight and all of them were lean $\left(\mathrm{BMI}<25 \mathrm{~kg} / \mathrm{m}^{2}\right)$.

The study had been approved by the local Ethical Committees and all the patients provided informed consent.

\section{Methods}

After an overnight fast, all subjects underwent both total IGF-I measurement and GHRH + ARG test (GHRH1-29; GEREF, Serono, Italy; $1 \mu \mathrm{g} / \mathrm{kg}$ i.v. at $0 \mathrm{~min}$; ARG hydrochloride, $0.5 \mathrm{~g} / \mathrm{kg}$ i.v. over $30 \mathrm{~min}$ from 0 to $+30 \mathrm{~min}$, up to a maximum of $30 \mathrm{~g}$ ). Blood samples for $\mathrm{GH}$ evaluation were taken every $15 \mathrm{~min}$ from 0 to $+90 \mathrm{~min}$.

The measurement of both serum GH and total IGF-I concentrations was centralized and performed using the laboratory of the Division of Endocrinology and Metabolism, University of Turin.

Serum GH was assayed by immunoradiometric method assay (IRMA) method (HGH-CTK IRMA; Diasorin, Saluggia, Italy). All samples from an individual subject were analyzed together. The Se of the method was $0.15 \mu \mathrm{g} / \mathrm{l}$. The inter- and intra-assay coefficients of variation were $3.5-4.4$ and $5.1-7.5 \%$ respectively at $\mathrm{GH}$ levels of $1.98-41.92$ and $2.99-42.45 \mu \mathrm{g} / \mathrm{l}$ respectively.

Serum total IGF-I was assayed by RIA method (SM-CRIA-CT; Pantec, Turin, Italy) after acid-ethanol extraction to avoid interference by binding proteins. The Se of the method was $0.1 \mu \mathrm{g} / \mathrm{l}$. The inter- and intraassay coefficients of variation were 5.0-9.5 and $8.8-10.8 \%$ respectively at IGF-I levels of 79.41-712.3 and $79.6-766.4 \mu \mathrm{g} / \mathrm{l}$ respectively.

\section{Statistical analysis}

Results are expressed as mean \pm s.e.m. of absolute values $(\mu \mathrm{g} / \mathrm{l})$. For IGF-I levels, age-adjusted SDS were also calculated. The normality of data distribution was confirmed by the Shapiro-Wilk test. Comparison of mean values between two different categories of the considered variables was performed using Student's $t$-test or by oneway ANOVA among groups. Age differences among groups and age differences in peak GH to the GHRH + ARG test and in individual total IGF-I levels both in controls and in the subgroups of patients were evaluated by ANOVA. Correlations between IGF-I and peak GH response to the GHRH + ARG test and between age and peak GH response to GHRH + ARG or to IGF-I levels were analyzed with Pearson's coefficient. A $P$ value of $<0.05$ was considered statistically significant. Receiver operating curve (ROC) analysis was used for the evaluation of the cut-off points (Medcalc 7.2). The lowest limit of normality for peak $\mathrm{GH}$ responses to the GHRH + ARG test for the diagnosis of probable permanent GHD during adolescence was defined as the value that provided the best pair of Se/Sp values (19). Se was calculated as the number of true-positive (TP) cases out of the sum of TP plus false-negative cases $(\mathrm{TP} /(\mathrm{TP}+\mathrm{FN}))$ and $\mathrm{Sp}$ was calculated as the number of true-negative cases out of the sum of true-negative plus false-positive cases $(\mathrm{TN} /(\mathrm{TN}+\mathrm{FP}))$. For the purpose of ROC curve analysis we assumed that the panhypopituitary patients (subgroup A) had GHD, according to other studies and the statement derived from either the Growth Hormone Research Society consensus or the recent Endocrine Society Clinical Practice Guidelines for adult GHD, suggesting increased likelihood of GHD and increased number of other pituitary hormone deficits $(1,20)$. The other two subgroups of patients (B and $\mathrm{C}$ : patients without or with no more than two pituitary hormonal deficits) included subjects with probably either normal or impaired GH secretion, in which the presence of GHD had to be verified.

ROC curves are constructed by plotting the Se on the ordinate as a function of the complement of the Sp for all the possible cut-off values of the diagnostic test. Each point of the ROC curves represents a Se/Sp pair corresponding to a particular decision threshold. The area under the ROC curve (ROC AUC) represents the probability of correctly distinguishing between affected and non-affected individuals. A perfect diagnostic test has a ROC curve that passes through the upper lefthand corner $(\mathrm{AUC}=1)$, where the TP fraction is 1.0 or $100 \%$ (perfect Se) and the FP fraction is 0 (perfect Sp). 
Tests with an AUC of $<0.5$ would not discriminate between affected and non-affected subjects (21).

The diagnostic cut-off points were calculated for both peak GH response to the GHRH + ARG test and individual IGF-I levels. To provide optimal separation of GHD and normal subjects, we applied two criteria: 1) to minimize misclassification of control subjects and GHD, balancing between high Se and high Sp and 2) to provide the highest pair of Se and Sp values for GHD.

For each of the cut-off points calculated by the ROC curve analysis, the accuracy value, defined as the number of true cases out of the total number of subjects studied, was also provided.

\section{Results}

\section{Peak GH response to the GHRH + ARG test}

No statistically significant differences were present in adult height, weight, or BMI among subgroups of patients or between those with congenital or acquired GHD.

No age or gender differences were found between controls and patients or among subgroups of patients.

Neither age difference nor correlation was found in mean peak $\mathrm{GH}$ response to the GHRH + ARG test and age among groups, both in controls and in subgroups of patients.

The mean peak GH in control subjects (69.3 \pm $2.6 \mu \mathrm{g} / \mathrm{l})$ was significantly higher than that in patients $(P<0.0001)$. Among the subgroups of patients, the mean peak $\mathrm{GH}$ response to the GHRH + ARG test was significantly different $(P<0.0001)$. In particular, in subgroup A peak GH $(3.4 \pm 0.8 \mu \mathrm{g} / \mathrm{l})$ was lower than that found in subgroup B $(18.1 \pm 8.2 \mu \mathrm{g} / \mathrm{l} ; P<0.05)$ and both were significantly lower than that found in subgroup C (42.4 $\pm 3.6 \mu \mathrm{g} / \mathrm{l} ; P<0.001$; Fig. 1, Table 3). Peak GH response to GHRH + ARG ranged between 0.1 and $19.0 \mu \mathrm{g} / \mathrm{l}$ in panhypopituitary patients (subgroup A) and between 0.1 and $150.8 \mu \mathrm{g} / \mathrm{l}$ in the

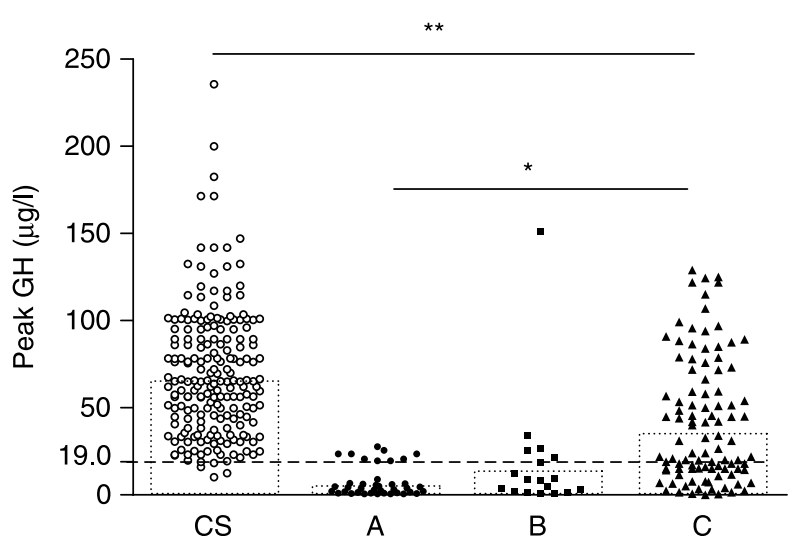

Figure 1 Mean (dotted squares) and individual peaks of $\mathrm{GH}$ response to the $\mathrm{GHRH}+\mathrm{ARG}$ test in subgroups of patients and in control subjects $\left({ }^{\star *} P<0.0001\right.$ between $\mathrm{CS}$ and patients; ${ }^{\star} P<0.05$ among subgroups of patients). other subgroups of patients (subgroups B and C), potentially affected by GHD, and between 9.7 and $235.0 \mu \mathrm{g} / \mathrm{l}$ in the controls (Fig. 1).

The GH peaks always occurred between 30 and $60 \mathrm{~min}$.

ROC curve analysis Regarding the ROC curve analysis for the GHRH + ARG test, the best pair of values with the highest Se (100\%) and the highest Sp (97\%) was found using a peak GH cut-off point of $19.0 \mu \mathrm{g} / \mathrm{l}$, with an accuracy of $81.5 \%$ (Fig. 2; Table 4 ).

Applying the cut-off points to the GHRH + ARG test of $19.0 \mu \mathrm{g} / \mathrm{l}$, we found that among the subgroup B 13 out of 18 patients $(72.2 \%)$ resulted $\mathrm{GHD}$, whereas in the subgroup C 39 out of 99 (39.4\%) resulted as affected by a persistent form of GHD.

By adopting the current published GH cut-off points for the GHRH+ARG test $(20 \mu \mathrm{g} / \mathrm{l}$ in pediatric population (20) and $9.0 \mu \mathrm{g} / \mathrm{l}$ in adult population (1-3)) none and 2 out of $35(5.7 \%)$ of the panhypopituitary adolescent patients would be excluded from a correct diagnosis of GHD respectively.

IGF-I levels Individual total IGF-I levels (mean \pm s.E.M.) and IGF-I SDS (mean \pm s.E.M.) were significantly higher in control subjects $(310.1 \pm 6.1 \mu \mathrm{g} / \mathrm{l}$ and $-0.4 \pm 0.1)$ than in patients $(P<0.0001)$. Among the subgroups of patients, IGF-I levels were significantly different $(P<0.0001)$. In particular, in subgroup A, IGF-I levels $(86.7 \pm 12.9 \mu \mathrm{g} / \mathrm{l}$ and $-1.97 \pm 0.1)$ were lower than those found in subgroup B $(157.1 \pm 34.8 \mu \mathrm{g} / \mathrm{l}$ and $-1.4 \pm 0.2$; $P<0.05)$ and in subgroup $C(225.5 \pm 18.1 \mu \mathrm{g} / \mathrm{l}$ and $-1.07 \pm 0.1 ; P<0.0001)$, whereas in subgroups $B$ and C IGF-I levels were similar (Fig. 3, Table 3).

There were no age or gender differences in mean IGF-I levels in patients or control groups.

No age or gender differences were found between control and patient groups or among subgroups of patients.

Neither age difference nor correlation were found in mean total individual IGF-I levels among control and patient subgroups.

ROC curve analysis Regarding the ROC curve analysis for IGF-I levels, the best pair of values for highest Se $(96.6 \%)$ and highest $\mathrm{Sp}(74.6 \%)$ was found using a peak GH cut-off point of $160 \mu \mathrm{g} / \mathrm{l}$ (IGF-I SDS: -1.3 ), with an accuracy of $70.8 \%$ (Fig. 4; Table 4).

Considering the whole population studied, individual total IGF-I levels were significantly and positively correlated $(r=0.4 ; P<0.001)$ to individual peak $\mathrm{GH}$ responses to GHRH+ARG test.

In patients of subgroups $\mathrm{B}$ and $\mathrm{C}$ who were found to be GHD by adopting the cut-off response to the GHRH+ARG test of $19.0 \mu \mathrm{g} / \mathrm{l}$, IGF-I levels were significantly lower than in those without GHD $(182.3 \pm 21.0 \mu \mathrm{g} / \mathrm{l}$ versus $374.5 \pm$ $30.2 \mu \mathrm{g} / \mathrm{l}$ in subgroup B, $P<0.05$ and $182.3 \pm 21.0 \mu \mathrm{g} / \mathrm{l}$ versus $272.3 \pm 33.4 \mu \mathrm{g} / \mathrm{l}$ in subgroup $\mathrm{C}, P<0.05)$. 
Table 3 Mean ( \pm S.E.M.) peak growth hormone $(\mathrm{GH})$ response to the GH-releasing hormone $(\mathrm{GHRH})+\operatorname{arginine}(\mathrm{GHRH}+\mathrm{ARG})$ test, individual total insulin-like growth factor-I (IGF-I) levels, and IGF-I SDS in the population studied.

\begin{tabular}{lcccc}
\hline & & \multicolumn{3}{c}{ Patients } \\
\cline { 3 - 5 } & Control & $\begin{array}{c}\text { Subgroup A } \\
\text { (panhypopituitary } \\
\text { patients) }\end{array}$ & $\begin{array}{c}\text { Subgroup B } \\
\text { (1 or 2 pituitary } \\
\text { hormone deficits) }\end{array}$ & $\begin{array}{c}\text { Subgroup C } \\
\text { (no pituitary hormone } \\
\text { deficits known) }\end{array}$ \\
\hline GH $(\mu \mathrm{g} / \mathrm{l})$ & $69.3 \pm 2.6^{*}$ & $3.4 \pm 0.8^{*, \dagger}$ & $18.1 \pm 8.2^{*, \dagger}$ & $42.4 \pm 3.6^{*}$ \\
IGF-I $(\mu \mathrm{g} / \mathrm{l})$ & $310.1 \pm 6.1^{*}$ & $86.7 \pm 12.9^{*,+, \S}$ & $157.1 \pm 34.8^{*}$ & $225.5 \pm 18.1^{*}$ \\
IGF-I SDS & $-0.4 \pm 0.1^{*}$ & $-1.97 \pm 0.1^{*,+, \S}$ & $-1.4 \pm 0.2^{*}$ & $-1.07 \pm 0.1^{*}$ \\
\hline
\end{tabular}

${ }^{\star} P<0.0001$ among groups and between control subjects and patients; ${ }^{\dagger} P<0.001$ subgroups $\mathrm{A}$ and $\mathrm{B}$ versus subgroup $\mathrm{C} ;{ }^{\ddagger} P<0.05$ versus subgroup $\mathrm{B}$; ${ }^{\S} P<0.0001$ versus subgroup $C$.

Moreover, IGF-I levels were $<160 \mu \mathrm{g} / \mathrm{l}$ (or less than -1.3 SDS) in $68.7 \%$ and in $41.6 \%$ of patients who resulted as GHD (peak GH below $19.0 \mu \mathrm{g} / \mathrm{l}$ ) belonging to subgroups B and $\mathrm{C}$ respectively.

On the other hand, IGF-I levels were below $160 \mu \mathrm{g} / \mathrm{l}$ in 30 out of 35 panhypopituitary patients (subgroup A), who had GHD demonstrated by GH peak response to GHRH+ARG test below $19.0 \mu \mathrm{g} / \mathrm{l}$. Thus low IGF-I levels could predict severe GHD in $85.7 \%$ of this population.

Finally, in subgroups of patients in whom GHD was demonstrated, this pituitary deficit was isolated in 39 out of $87(44.9 \%)$ cases and associated with other pituitary deficits in 48 out of $87(55.1 \%)$ cases.

The cut-off points with the best pair of values for $\mathrm{Se} / \mathrm{Sp}$ for the GHRH + ARG test and IGF-1 levels, with confidence intervals at $95 \%$, are shown in Table 4.

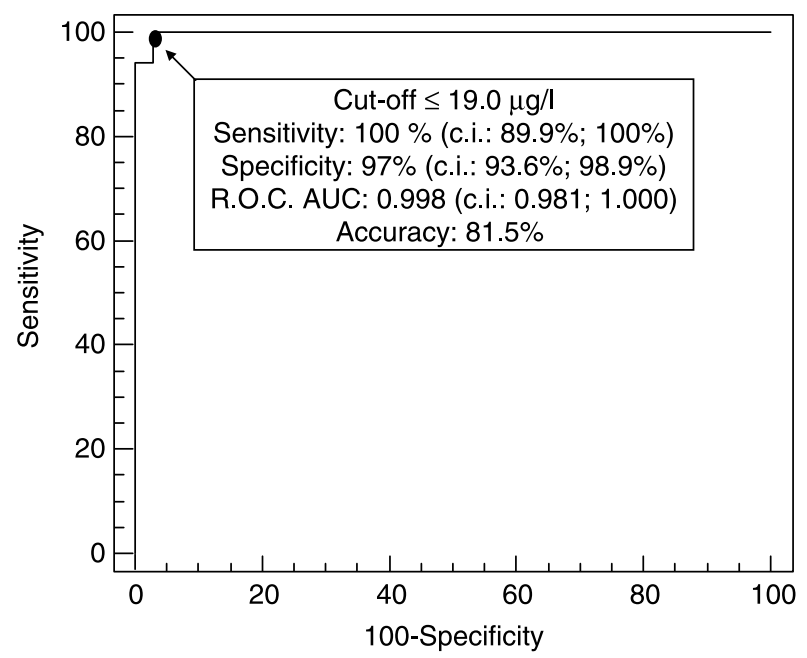

Figure 2 ROC curves for peak serum $\mathrm{GH}$ responses to the $\mathrm{GHRH}+$ ARG test in the lean adolescent and young adult population. The arrow indicates the location on the ROC curves of the diagnostic cut-off point that minimizes misclassification of panhypopituitary patients and control subjects. The cut-off point, sensitivity and specificity, with their confidence intervals (c.i.) at 95\%, ROC AUC and accuracy are shown in the box.

\section{Discussion}

The results of this study firstly provide cut-off limits for the GH response to the GHRH + ARG test and IGF-I levels for lean late adolescents and young adults who are suspected for GHD, either isolated or in association with other pituitary deficits.

Data about normative cut-off levels in late adolescence and young adulthood are scarce. This applies to GH/IGF-I axis whose function and response to stimulation during this period of life has never been systematically defined. Consequently, the diagnosis of GHD in late adolescence and young adulthood cannot rely on definite normative data. This is clearly indicated by the Consensus Statement on the management of the GH-treated adolescent in the transition to adult care that indicated the GH cut-off point for the diagnosis of GHD in a peak lower than $5 \mu \mathrm{g} / \mathrm{l}$ (4). Indeed, this cut-off point was not evidence based and simply indicated a value in between the cut-off points of 7 and $3 \mu \mathrm{g} / \mathrm{l}$; these cut-offs are generally adopted for the diagnosis of GHD in childhood and adulthood respectively $(19,22,23)$ and reflect the assumption that $\mathrm{GH}$ secretion declines through aging (23-26). Actually, although ITT was assumed by this Consensus as the test of choice, the recommendation generally referred to any provocative test (4).

It is widely accepted that the diagnostic cut-off levels have to be defined in an appropriate population for each provocative test $(1,19)$. In a previous study, we were first to define the appropriate diagnostic cut-off limits of $\mathrm{GH}$ response to the ITT test in late adolescents and

Table 4 Cut-off points of peak growth hormone $(\mathrm{GH})$ response to GH-releasing hormone + arginine (GHRH + ARG) test, individual total insulin-like growth factor-I (IGF-I) levels, and IGF-I SDS with their best pair of values for sensitivity and specificity in late adolescent and young adult population.

\begin{tabular}{lcc}
\hline & $\begin{array}{c}\text { GHRH + ARG } \\
\text { test }\end{array}$ & IGF-I levels \\
\hline Cut-off point $(\mu \mathrm{g} / \mathrm{l})$ & 19.0 & $160(-1.3 \mathrm{SDS})$ \\
Sensitivity $(\% ; 95 \%$ c.i.) & $100(89.9 ; 100)$ & $96.6(93.0 ; 98.6)$ \\
Specificity $(\% ; 95 \%$ c.i.) & $97(93.6 ; 98.9)$ & $74.6(68.6 ; 80.9)$ \\
Accuracy $(\%)$ & 81.5 & 70.8 \\
\hline
\end{tabular}




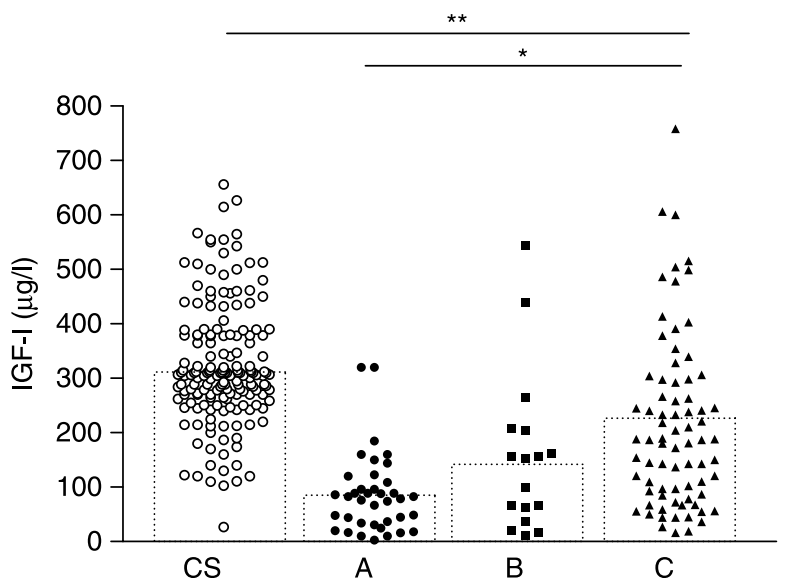

Figure 3 Mean (dotted squares) and individual IGF-I levels in subgroups of patients and in control subjects ${ }^{* \star} P<0.0001$ between CS and patients; ${ }^{*} P<0.05$ among subgroups of patients).

young adults as GH peak below $6.1 \mu \mathrm{g} / \mathrm{l}$ with a Se of $96 \%$ and a Sp of $100 \%$ (11). Thus, whenever the test of choice for the diagnosis of GHD during this period of life is ITT, one should refer to this cut-off level. Some physicians concerns remain about the poor reproducibility of ITT, questioning its $\operatorname{Sp}(27,28)$. Moreover, hypoglycemia may be contraindicated in some clinical conditions and it is generally not well tolerated $(22,29)$, in particular in adolescents and young adults with a clinical history of organic pituitary disease.

In this study, we aimed to appropriately define using the ROC curve analysis the cut-off levels of the normal $\mathrm{GH}$ response to GHRH + ARG that is considered as reliable as ITT for the diagnosis of adult $\operatorname{GHD}(1,12,22$, 30). It is well known that GHRH + ARG test demonstrated excellent Se and Sp both in childhood and in

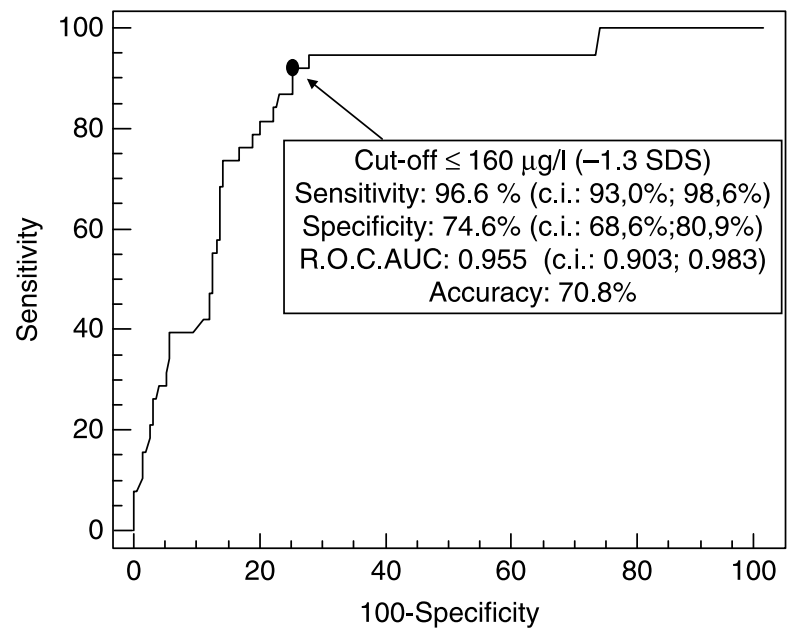

Figure 4 ROC curves for IGF-I levels in the lean adolescent and young adult population. The arrow indicates the location on the ROC curves of the diagnostic cut-off point that minimizes misclassification of panhypopituitary patients and control subjects. The cut-off point, sensitivity and specificity, with their confidence intervals (c.i.) at 95\%, ROC AUC and accuracy are shown in the box. adulthood assuming appropriate cut-off limits (12, 14-16) but normative data in late adolescence and young adulthood were lacking. Although the use of the GHRH + ARG test is questioned regarding its ability to diagnose GHD in subjects in whom the defect is represented by hypothalamic impairment, namely GHRH deficiency (e.g., after hypothalamic-pituitary irradiation) (31), it is actually increasingly used and the results obtained with this test strongly correlate with those obtained by testing with ITT $(14,31)$.

Our present data show that a cut-off limit of $19.0 \mu \mathrm{g} / \mathrm{l}$ after the GHRH + ARG test in adolescence is reliable both as a screening and a diagnostic test in a population suspected for GHD in adolescents and young adults, because of its high Se (100\%) and high Sp (97\%). This is highly essential as the GHRH + ARG test should be used as a first-step diagnostic test rather than a screening test. Moreover, this cut-off overlaps with that considered for diagnosis of GHD in childhood (i.e., $20.0 \mu \mathrm{g} / \mathrm{l}$ ) (22) and is about twofold higher than that recommended for the diagnosis of GHD in adults (i.e., $9.0 \mu \mathrm{g} / \mathrm{l})(1,12,14,15)$. Thus, the first consideration is that the evaluation of the maximal secretory capacity of somatotroph cells by GHRH + ARG in late adolescents and young adults allows showing normative levels that are similar to those in children and still higher than in adults. Indeed, this evidence emphasizes the importance of considering cut-off levels as a function of the phase of life.

The definition of cut-off points by ROC curve analysis is the most appropriate in order to provide the best pair of values for Se/Sp (21). In fact, a high Se/Sp cut-off point (i.e., $19.0 \mu \mathrm{g} / \mathrm{l}$ ) maximizes detection of adult GHD and minimizes misclassification of normal subjects as $\mathrm{GH}$ deficient. In our study, these cut-off limits were found to have a pair of Se/Sp values similar to the ideal of $95 \%$ that might be considered the most appropriate either to clearly reconfirm the diagnosis of pediatric GHD or to exclude GHD if the clinical suspicion is low. It remains that these cut-off points referred to the $\mathrm{GH}$ assay used in this study and the remarkable variability among different assays is well known (32). Again, it has to be noticed that these cut-off limits were established in lean subjects only; considering that $\mathrm{GH}$ secretion is a function of weight and adiposity (15, 33-35), cut-off limits appropriate for overweight and obese subjects remain to be defined.

Based on the definition of these cut-off values appropriate for late adolescents and young adults, our findings allow us to confirm that childhood-onset panhypopituitarism is always associated with severe GHD $(16,36,37)$. High risk for severe GHD $(72 \%)$ is also displayed by patients who had been treated with rhGH in childhood with only one or with no more than two other pituitary hormone deficits. However, also in the group of patients with suspected GHD, without any other current pituitary deficits, as high as $40 \%$ of the patients showed a persistent GHD needing rhGH substitutive therapy in adult age. 
Moreover, we evaluated by ROC curve analysis the cutoff limit for total IGF-I levels for adolescent and young adults. The cut-off limit of $160 \mu \mathrm{g} / \mathrm{l}$ (or -1.3 SDS) would have identified more than $87 \%$ of panhypopituitary patients with severe GHD and almost $50 \%$ of the patients affected by one or two pituitary hormone defects, other than suspected GHD, and in the group of patients who were not known to be affected by pituitary hormone deficiencies other than GH during childhood, suggesting that low IGF-I levels are able to strongly predict severe GHD also in late adolescents and young adults. Furthermore, despite the lower diagnostic pair of Se/Sp of this parameter very low levels of total IGF-I can be considered definitive evidence of severe GHD in a remarkable percentage of patients (especially in panhypopituitary patients) who could therefore skip provocative tests for $\mathrm{GH}$ secretion (7). However, although even in patients with total anterior hypopituitarism total IGF-I levels are often normal, this finding cannot rule out severe GHD that therefore ought to be verified by provocative testing of $\mathrm{GH}$ secretion and it is always mandatory to verify the suspicion of isolated GHD. These findings agree with those recorded in a previous study performed in another cohort of patients (11).

In conclusion, even considering the need to refer to age-related hormonal cut-off limits specific for each provocative test, our findings further demonstrate and strengthen the reliability of GHRH+ARG as a provocative test in adolescent and young adult patients in order to clearly reevaluate the $\mathrm{GH}$ secretion in the transition period. Although the cut-off values in infancy and in adolescents and young adults are similar, the $\mathrm{GHRH}+\mathrm{ARG}$ test has a great accuracy and diagnostic value.

\section{Acknowledgements}

This study was partially supported by FSMEM and University of Turin, Italy.

\section{References}

1 Growth Hormone Research Society. Consensus guidelines for the diagnosis and treatment of adults with growth hormone deficiency: summary statement of the Growth Hormone Research Society Workshop on Adult Growth Hormone Deficiency. Journal of Clinical Endocrinology and Metabolism 199883 379-381.

2 Abs R. Update on the diagnosis of GH deficiency in adults. European Journal of Endocrinology $2003 \mathbf{1 4 8}$ S3-S8.

3 Gharib H, Cook DM, Saenger PH, Bengtsson BA, Feld S, Nippoldt TB, Rodbard HW, Seibel JA, Vance ML, Zimmerman D, Palumbo PJ, Bergman DA, Garber JR, Hamilton CR Jr, Petak SM, Rettinger HI, Service FJ, Shankar TP, Stoffer SS, Tourletot JB \& the American Association of Clinical Endocrinologists Growth Hormone Task Force. American Association of Clinical Endocrinologists medical guidelines for clinical practice for growth hormone use in adults and children - 2003 update. Endocrine Practice 20039 64-76.
4 Clayton PE, Cuneo RC, Juul A, Monson JP, Shalet SM, Tauber M \& the European Society of Paediatric Endocrinology. Consensus statement on the management of the GH-treated adolescent in the transition to adult care. European Journal of Endocrinology 2005 152 165-170 (Review).

5 Rosenfeld RG, Albertsson-Wikland K, Cassorla F, Frasier SD, Hasegawa Y, Hintz RL, Lafranchi S, Lippe B, Loriaux L Melmed S et al. Diagnostic controversy: the diagnosis of childhood growth hormone deficiency revisited. Journal of Clinical Endocrinology and Metabolism 199580 1532-1540.

6 Hartman ML, Crowe BJ, Biller BM, Ho KK, Clemmons DR \& Chipman JJ. Which patients do not require a GH stimulation test for the diagnosis of adult $\mathrm{GH}$ deficiency? Journal of Clinical Endocrinology and Metabolism 200287 477-485.

7 Aimaretti G, Corneli G, Baldelli R, Di Somma C, Gasco V, Durante C, Ausiello L, Rovere S, Grottoli S, Tamburrano G \& Ghigo E. Diagnostic reliability of a single IGF-I measurement in 237 adults with total anterior hypopituitarism and severe $\mathrm{GH}$ deficiency. Clinical Endocrinology 200359 56-61.

8 Cianfarani S, Liguor A, Boemi S, Maghnie M, Iughetti L, Wasniewska M, Street ME, Zucchini S, Aimaretti G \& Germani D. Inaccuracy of insulin-like growth factor (IGF) binding protein (IGFBP)-3 assessment in the diagnosis of growth hormone (GH) deficiency from childhood to young adulthood: association to low GH dependency of IGF-II and presence of circulating IGFBP-3 18-kilodalton fragment. Journal of Clinical Endocrinology and Metabolism $2005906028-6034$.

9 Aimaretti G, Baldelli R, Corneli G, Croce C, Rovere S, Baffoni C, Bellone S, Gasco S, Granata R, Grottoli S \& Ghigo E. IGFs and IGFBPs in adult growth hormone deficiency. Endocrine Development 20059 76-88 (Review).

10 Aimaretti G, Corneli G, Rovere S, Granata R, Baldelli R, Grottoli S \& Ghigo E. Insulin-like growth factor I levels and the diagnosis of adult growth hormone deficiency. Hormone Research $2004 \mathbf{6 2}$ 26-33 (Review).

11 Maghnie M, Aimaretti G, Bellone S, Bona G, Bellone J, Baldelli R, de Sanctis C, Gargantini L, Gastaldi R, Ghizzoni L, Secco A, Tinelli C \& Ghigo E. Diagnosis of GH deficiency in the transition period: accuracy of insulin tolerance test and insulin-like growth factor-I measurement. European Journal of Endocrinology 2005152 589-596.

12 Aimaretti G, Baffoni C, DiVito L, Bellone S, Grottoli S, Maccario M, Arvat E, Camanni F \& Ghigo E. Comparisons among old and new provocative tests of GH secretion in 178 normal adults. European Journal of Endocrinology 2000142 347-352.

13 Aimaretti G, Corneli G, Bellone S, Baffoni C, Camanni F \& Ghigo E. Growth hormone deficiency in the transition adolescent: should treatment be continued in adult life? Journal of Pediatric Endocrinology and Metabolism 200114 (Suppl 5) 1233-1242.

14 Ghigo E, Aimaretti G, Arvat E \& Camanni F. Growth hormone releasing hormone combined with arginine or growth hormone secretagogues for the diagnosis of growth hormone deficiency in adults. Endocrine 200115 29-38.

15 Corneli G, Di Somma C, Baldelli R, Rovere S, Gasco V, Croce CG, Grottoli S, Maccario M, Colao A, Lombardi G, Ghigo E, Camanni F \& Aimaretti G. The cut-off limits of the GH response to GH-releasing hormone-arginine test related to body mass index. European Journal of Endocrinology 2005153 257-264.

16 Aimaretti G, Baffoni C, Bellone S, Di Vito L, Corneli G, Arvat E, Benso L, Camanni F \& Ghigo E. Retesting young adults with childhood-onset growth hormone (GH) deficiency with GH-releasing-hormone-plus-arginine test. Journal of Clinical Endocrinology and Metabolism 200085 3693-3699.

17 Maghnie M, Salati B, Bianchi S, Rallo M, Tinelli C, Autelli M, Aimaretti G \& Ghigo E. Relationship between the morphological evaluation of the pituitary and the growth hormone $(\mathrm{GH})$ response to GH-releasing hormone plus arginine in children and adults with congenital hypopituitarism. Journal of Clinical Endocrinology and Metabolism 200186 1574-1579. 
18 Maghnie M, Cavigioli F, Tinelli C, Autelli M, Arico M, Aimaretti G \& Ghigo E. GHRH plus arginine in the diagnosis of acquired $\mathrm{GH}$ deficiency of childhood-onset. Journal of Clinical Endocrinology and Metabolism 200287 2740-2744.

19 Growth Hormone Research Society. Consensus guidelines for the diagnosis and treatment of growth hormone $(\mathrm{GH})$ deficiency in childhood and adolescence: summary statement of the $\mathrm{GH}$ Research Society. Journal of Clinical Endocrinology and Metabolism $2000853990-3993$.

20 Molitch ME, Clemmons DR, Malozowski S, Merriam GR, Shalet SM, Vance ML. Endocrine Society's Clinical Guidelines Subcommittee \& Stephens PA. Evaluation and treatment of adult growth hormone deficiency: an Endocrine Society Clinical Practice Guideline. Journal of Clinical Endocrinology and Metabolism 200691 1621-1634.

21 Zweig MH \& Campbell G. Receiver-operating characteristic (ROC) plots: a fundamental evaluation tool in clinical medicine. Clinical Chemistry 199339 561-577.

22 Ghigo E, Bellone J, Aimaretti G, Bellone S, Loche S, Cappa M, Bartolotta E, Dammacco F \& Camanni F. Reliability of provocative tests to assess growth hormone secretory status. Study in 472 normally growing children. Journal of Clinical Endocrinology and Metabolism 199681 3323-3327.

23 Ghigo E, Arvat E, Gianotti L, Lanfranco F, Broglio F, Aimaretti G, Maccario M \& Camanni F. Hypothalamic growth hormone-insulinlike growth factor-I axis across the human life span. Journal of Pediatric Endocrinology and Metabolism 200013 (Suppl 6) 14931502.

24 Zadik Z, Chalew SA, McCarter RJ Jr, Meistas M \& Kowarski AA. The influence of age on the 24-hour integrated concentration of growth hormone in normal individuals. Journal of Clinical Endocrinology and Metabolism 198560 513-516.

25 Iranmanesh A, Lizarralde G \& Veldhuis JD. Age and relative adiposity are specific negative determinants of the frequency and amplitude of growth hormone $(\mathrm{GH})$ secretory bursts and the halflife of endogenous $\mathrm{GH}$ in healthy men. Journal of Clinical Endocrinology and Metabolism 199173 1081-1088.

26 Veldhuis JD \& Iranmanesh A. Physiological regulation of the human growth hormone $(\mathrm{GH})$-insulin-like growth factor type I (IGF-I) axis: predominant impact of age, obesity, gonadal function, and sleep. (Review) Sleep 199619 (Suppl 10) S221-S224.

27 Hoeck HC, Vestergaard P, Jakobsen PE \& Laurberg P. Test of growth hormone secretion in adults: poor reproducibility of the insulin tolerance test. European Journal of Endocrinology 1995133 305-312.

28 Vestergaard P, Hoeck HC, Jakobsen E \& Laurbarg P. Reproducibility of growth hormone and cortisol responses to the insulin tolerance test and the short ACTH test in normal adults. Hormone and Metabolic Research 199729 106-110.
29 Maghnie M, Strigazzi C, Tinelli C, Autelli M, Cisternino M, Loche S \& Severi F. Growth hormone (GH) deficiency (GHD) of childhood onset: reassessment of $\mathrm{GH}$ status and evaluation of the predictive criteria for permanent GHD in young adults. Journal of Clinical Endocrinology and Metabolism 199984 1324-1328.

30 Aimaretti G, Corneli G, Razzore P, Bellone S, Baffoni C, Arvat E, Camanni F \& Ghigo E. Comparison between insulin-induced hypoglycemia and growth hormone $(\mathrm{GH})$-releasing hormone + arginine as provocative tests for the diagnosis of GH deficiency in adults. Journal of Clinical Endocrinology and Metabolism $1998 \mathbf{8 3}$ 1615-1618.

31 Darzy KH, Aimaretti G, Wieringa G, Gattamaneni HR, Ghigo E \& Shalet SM. The usefulness of the combined growth hormone (GH)releasing hormone and arginine stimulation test in the diagnosis of radiation-induced $\mathrm{GH}$ deficiency is dependent on the postirradiation time interval. Journal of Clinical Endocrinology and Metabolism $2003 \mathbf{8 8}$ 95-102.

32 Strasburger CJ \& Bidlingmaier M. How robust are laboratory measures of growth hormone status? Hormone Research 200564 $1-5$.

33 Maccario M, Valetto MR, Savio P, Aimaretti G, Baffoni C, Procopio M, Grottoli S, Oleandri SE, Arvat E \& Ghigo E. Maximal secretory capacity of somatotrope cells in obesity: comparison with GH deficiency. International Journal of Obesity and Related Metabolic Disorders 199721 27-32.

34 Bonert VS, Elashoff JD, Barnett P \& Melmed S. Body mass index determines evoked growth hormone $(\mathrm{GH})$ responsiveness in normal healthy male subjects: diagnostic caveat for adult $\mathrm{GH}$ deficiency. Journal of Clinical Endocrinology and Metabolism 2004 89 3397-3401.

35 Qu XD, Gaw Gonzalo IT, Al Sayed MY, Cohan P, Christenson PD, Swerdloff RS, Kelly DF \& Wang C. Influence of body mass index and gender on growth hormone (GH) responses to $\mathrm{GH}$-releasing hormone plus arginine and insulin tolerance tests. Journal of Clinical Endocrinology and Metabolism $2005901563-1569$.

36 Tauber M, Moulin P, Pienkowski C, Jouret B \& Rochiccioli P. Growth hormone $(\mathrm{GH})$ retesting and auxological data in 131 $\mathrm{GH}$-deficient patients after completion of treatment. Journal of Clinical Endocrinology and Metabolism 199782 352-356.

37 Attanasio AF, Howell S, Bates PC, Blum WF, Frewer P, Quigley C \& Shalet SM. Confirmation of severe GH deficiency after final height in patients diagnosed as $\mathrm{GH}$ deficient during childhood. Clinical Endocrinology 200256 503-507.

Received 9 September 2007

Accepted 17 September 2007 